\title{
SABER CIENTÍFICO, SABER ESCOLAR E SUAS RELAÇÕES: elementos para reflexão sobre a didática
}

\section{Scientific knowledge, school knowledge and their relations: elements of consideration over didactics}

Wagner Rodrigues Valente*

\section{Resumo}

O texto pretende analisar as contribuições que podem ser dadas pela Nova História das Ciências (NHC) para a análise das relações existentes entre saberes científicos e saberes escolares, em meio às duas vertentes teóricas citadas, que vêm se constituindo como bases privilegiadas para a pesquisa sobre o assunto. Para tanto, busca, de início, sintetizar as discussões travadas no âmbito da história das disciplinas escolares e no campo da didática das disciplinas, procurando caracterizar como esses campos teóricos enfocam as relações entre os saberes. Num segundo momento, procura verificar que contribuições podem ser dadas pela NHC para a compreensão do significado dos saberes escolares e, finalmente, intenta elaborar a crítica das posições que apartam conhecimento científico e escolar, de modo a contribuir com elementos importantes para reflexão sobre a Didática.

Palavras-chave: Didática, História das Ciências, Saberes.

* Professor do Programa de Pós-Graduação em Educação Matemática da PUC-SP.

Pontifícia Universidade Católica de São Paulo - Educação, Rua Monte Alegre, 984, Perdizes,

São Paulo - SP, CEP 05014-901.

E-mail: valente@pucsp. br 


\section{Abstract}

The text intends to analyze contributions that might be given by the New History of Sciences (NHC) to the analysis of relations between scientific knowledge and school knowledge, in face of the two cited theoretic lines, which have been constituting as privileged basis to research about the topic. In order to do it, it first aims at synthesizing discussions on the domain of the history of school subjects and on the field of subject didactics, in search of characterizing how these theoretic fields focus relations between forms of knowledge. In a second moment, it aims at verifying contributions that might be given by NHC to the understanding of the meaning of school knowledge, and finally, it intends to elaborate the criticism of views which part scientific knowledge to school knowledge, so to contribute with important elements of consideration over Didactics.

Keywords: Didactics, History of the Sciences, Knowledge.

Ao que tudo indica, o estudo das relações que envolvem os saberes escolares e os saberes científicos é bastante recente no Brasil.

Um olhar retrospectivo nos mostra que as discussões pedagógicas dos anos 1980 parecem não evidenciar a problemática das relações entre saberes científicos e escolares. Em meio à luta para a construção de uma pedagogia crítica, os textos, em sua quase totalidade, contentam-se em cunhar os saberes escolares genericamente como "conjunto dos elementos essenciais do conhecimento humano", "saber historicamente elaborado pela humanidade", "saberes universais", etc. ${ }^{1}$

O tema das relações entre os saberes científicos e escolares na década seguinte, no Brasil, passa a ser discutido em novas bases, constituindo uma verdadeira problemática, a partir dos campos denominados história das disciplinas escolares e didática das disciplinas. Tais campos advogam significados diferentes para as relações entre esses saberes.

Este texto pretende analisar as contribuições que podem ser dadas pela Nova História das Ciências (NHC), designação esta retirada do texto de Pestre (1996), para a análise das relações existentes entre saberes científicos e saberes escolares, em meio às duas vertentes teóricas citadas, que vêm se constituindo como bases privilegiadas para a pesquisa sobre o assunto. Para tanto, busca-se, de início, sintetizar as discussões travadas no âmbito da história das disciplinas escolares e no campo da didática das disciplinas, procurando caracterizar como esses campos teóricos enfocam as relações entre os saberes. Num segundo momento, procura-se verificar que contribuições podem ser dadas pela NHC para a compreensão do significado dos saberes escolares e, finalmente, intenta-se elaborar a crítica das posições que apartam conhecimento científico e escolar, de modo a contribuir com elementos importantes para a reflexão sobre a Didática. 
Saber científico, saber escolar e suas relações: Elementos para reflexão sobre a didática

\section{Os saberes científico e escolar sob a perspectiva da história das disciplinas}

Num texto já bastante difundido no Brasil - História das Disciplinas Escolares: reflexões sobre um campo de pesquisa, Chervel (1990) discute as relações entre as ciências, tratadas por ele como ciências de referência, e os saberes escolares, considerados sob a forma de disciplinas escolares, tendo por núcleo principal os conteúdos de ensino. O autor elabora uma exaustiva análise para compreensão do significado das disciplinas escolares. Seu trajeto inclui desde o estudo etimológico do termo disciplina, passando pela discussão sobre os ensinos escolares, suas finalidades etc., culminando na elaboração de uma verdadeira anatomia das disciplinas escolares. Feita a anatomia, o autor conclui que toda disciplina escolar representa uma combinação, em proporções variáveis, de um ensino de exposição, de exercícios, de práticas de incitação e de motivação e de um aparato de testes, provas e exames que lhe dão legitimidade e conformação (p. 207).

Os saberes escolares, para Chervel, contrariamente ao que se apregoa tradicionalmente, não representam vulgarização dos saberes científicos:

São concebidos como entidades sui generis, próprios da classe escolar, independentes, numa certa medida, de toda realidade cultural exterior à escola, e desfrutando de uma organização, de uma economia interna e de uma eficácia que elas não parecem dever a nada além delas mesmas, quer dizer à sua própria história (1990, p. 180).

As pesquisas de Chervel (1990) pretendem revelar-nos que as disciplinas escolares são criações espontâneas e originais do sistema escolar, isto é, a escola não vulgariza as ciências ou faz delas uma adaptação para os alunos; a escola constitui o lugar de criação das disciplinas (p. 184).

Desse modo, as disciplinas escolares constituem, ao mesmo tempo, produto histórico do trabalho escolar e instrumento de trabalho pedagógico. Tudo que tiver que ser ensinado no cotidiano escolar deverá, portanto, passar pelo crivo do disciplinar. Deverá conformar-se segundo o modelo disciplinar. O saber a ser transmitido na escola, produto que ela mesma elaborou historicamente, segundo Chervel (1990), vem sempre acondicionado no interior das disciplinas escolares.

Para compreender o significado dos saberes escolares, sob a ótica da história das disciplinas, faz-se necessário o estudo de uma das mais criativas produções culturais da escola: as disciplinas. Elas, finalmente, sentencia Chervel (1990), são o preço que a sociedade deve pagar à sua cultura para poder transmiti-la no contexto da escola ou do colégio (p. 222). 
Assim, parece-nos possível dizer, a partir da história das disciplinas, que o trabalho investigado que intente compreender os saberes presentes nos programas de ensino deve ocorrer, privilegiadamente, no intramuros da história da ambiência educativa. Envolvido com todo tipo de documentação escolar acumulada ao longo do tempo, o pesquisador terá por tarefa elaborar a narrativa que explicite a produção dos diferentes saberes escolares historicamente secretados pela escola. Esse trabalho, secundarizando a produção científica, buscaria entender por que se ensina nas escolas de nível fundamental e médio. E, ainda, como os diversos saberes, em sua trajetória para esquadrar-se e desenvolver-se segundo o modelo disciplinar, puderam ser escolarizados. Assim, como ponto de partida, e também com o resultado, a escrita dessa história revelaria a autonomia do saber escolar face ao saber científico.

\section{A didática das disciplinas e as relações entre os saberes científico e escolar}

No âmbito da didática das disciplinas, o trabalho de Yves Chevallard pode ser considerado como referência principal para discussão das relações entre os saberes científicos e escolares. A obra basilar de Chevallard é o livro La transposition didactique-du savoir savant au savoir enseigné. Nela, o autor caracteriza sistemas de saberes como savoir savant (saber científico) e savoir enseigné (saber ensinado). Assim, a categoria principal trabalhada pelo autor o conceito de transposição didática - designa a passagem do saber científico para o saber ensinado.

Mediante um modelo bastante sofisticado, Chevallard (1991) discute as relações entre os saberes, partindo, sobretudo, do exemplo do Movimento da Matemática Moderna. No modelo chevallardiano, saberes científicos e escolares relacionam-se por meio de fluxos de elementos do primeiro que se inserem no segundo, de tempos em tempos, em razão de crises no saber ensinado. Distinguindo esferas como sistema de ensino, noosfera e ambiente social, Chevallard (1991) procura mostrar que, partindo da premissa que todo sistema de ensino deve ter seu funcionamento compatível como o ambiente social em que se insere, há momentos em que essa compatibilidade se vê alterada. Chevallard (1991) considera que o uso do saber ensinado, com o tempo, produz um envelhecimento desse saber, o que leva à incompatibilização do sistema de ensino com o meio ambiente social (CHEVALARD, p. 26). Assim, por meio da esfera que pensa o funcionamento do sistema de ensino a noosfera - são alterados os programas, os conteúdos de ensino, de modo a que essas alterações no saber escolar possam fazer retornar a compatibilidade entre ambiente e sistema de ensino. No modelo da transposição didática, a compatibilidade em termos de saberes, 
... deve ser vista por uma dupla imposição. De um lado o saber ensinado o saber tratado no interior do sistema de ensino - deve ser visto pelos sábios/ cientistas, como suficientemente próximo do saber científico, a fim de não incorrer em desacordo com os matemáticos, o que minaria a legitimidade do projeto social de seu ensino. Por outro lado, e ao mesmo tempo, o saber ensinado deve aparecer como suficientemente distanciado do saber dos "paia", (...) quer dizer, o saber banalizado pela sociedade (e notoriamente banalizado pela escola!). (CHEVALLARD, 1991, p. 26)

Assim, é possível depreender que, pela didática das disciplinas - e 0 modelo da transposição didática expandiu-se para além da matemática escolar, sendo utilizado nas mais diversas disciplinas ${ }^{2}$ - as relações entre os saberes científicos e escolares ficam caracterizados sempre por uma transposição de conteúdos, que têm origem no saber científico, destinados a serem incorporados como conteúdos escolares. Tal incorporação é fruto de um trabalho de adaptação e reorganização dos saberes escolares promovida por uma instância distante da sala de aula, à parte do trabalho do professor, chamada noosfera. Grosso modo, a noosfera reúne os pais, os cientistas, as instâncias políticas e executivas dos ministérios encarregados da educação. Nela estão presentes aqueles que pensam como deve o sistema de ensino funcionar e o que deve ser ensinado.

0 entendimento dos saberes escolares, ancorado na teoria da transposição didática, dá-se a partir da análise da origem de conceitos que em algum momento fizeram parte do saber científico, e que sofreram um processo de transposição. Assim, dentro da perspectiva da didática das disciplinas, 0 significado dos conteúdos escolares deverá ser buscado na história das transposições efetuadas para constituí-lo.

\section{As relações entre saberes científicos e escolares: a Nova História das Ciências}

Dominique Pestre, num extenso artigo na revista Annales ESC em 1995, traduzido para o português, em 1996, sob o título "Por uma nova história social e cultural das ciências: novas definições, novos objetos, novas abordagens", realiza um inventário das novas tendências para escrita da história das ciências. Pestre destaca que a partir dos anos 1970, a história das ciências vem sofrendo uma renovação similar àquela pela qual passou a História nos anos 1930. Será a partir de suas considerações, nesse texto e também no artigo Lês sciences et l'histoire aujoud'hui, publicado em 1998, que procurará extrair elementos que evidenciem contribuições para a compreensão do significado dos saberes escolares, diferentemente daquilo que propõem as perspectivas 
vindas da história e da didática das disciplinas, sumariadas anteriormente.

A NHC desde logo vem procurando redefinir o que são práticas científicas. Nessa nova historiografia, o ponto inicial dos debates se dá por meio da recusa da imagem das ciências construída, sobretudo por Popper (PESTRE, 1998, p. 53). A redefinição do significado das práticas científicas se coloca contra o discurso dominante que torna as ciências enquanto sistemas de proposições, sistemas de enunciados que devem ser postos à prova em confronto com a experiência. Tal concepção, hoje dominante, valoriza em excesso a dimensão abstrata da produção científica e reifica a categoria de ciência, sem problematizá-la, tomando-a de modo a-histórico, isto é, transcendendo o tempo comum dos historiadores (PESTRE, 1996, p. 14).

Para Pestre (1996, p. 16-19), a redefinição operada pela NHC considera, dentre outras coisas, que:

1. É preferível abandonar a categoria de "Ciência" e usar o plural, ciências, para, sobretudo, fugir à reificação.

2. Diferentemente de considerar as ciências como conjunto de enunciados convém reconhecer que, tanto para as ciências teóricas como quanto para as ciên cias práticas ou experimentais, os saberes tácitos, o saber-fazer, as maneiras de fazer e de tratar concretamente os problemas vêm primeiro (...).

3. O cientista, aquele que pratica as ciências, é alguém que adquiriu uma cultura, que foi formado, modelado por um certo meio, que foi fabricado no contato com um grupo e com ele compartilhou atividades - e não uma consciência crítica operante, um puro sujeito conhecedor.

4. O fato de que os saberes científicos apareçam como bastante cumulativos (...) não resulta nem do emprego de um conjunto de regras lógicas ("o método científico") nem de comportamentos éticos ou sociais particulares.

5. A dinâmica das ciências não se reduz a uma dialética controvérsias-consensos, mas se apoia, sobretudo na circulação de objetos e de saberfazer.

A partir desses elementos fundamentais, a NHC debruça-se sobre novos objetos históricos como: história dos instrumentos, análises das práticas científicas, história dos cumprimentos da prova, tecnologias literárias, história das organizações e escolhas técnico-científicas.

A NHC, ao tomar como um de seus objetos de estudo as tecnologias literárias, possibilita, ao que tudo indica, uma nova abordagem para compreensão do significado dos saberes escolares. Assim, será preciso levar em conta que 
o texto científico é um objeto construído segundo regras variáveis no tempo e no espaço social, um objeto que seria ingênuo considerar transparente em si mesmo, como se relatasse fatos brutos. Aqui como nos outros domínios, o estudo das "traduções" sucessivas que os saberes conhecem - desde as cadernetas de laboratónio, a correspondência, os croquis, os rascunhos de artigos até as versões publicadas, os tratados, manuais de cursos, apresentações para não especialistas e conferências para o grande público -, desde há muito destacou que o status de evidência e de lógica dos resultados se modifica a cada contexto. Cada reescritura tem funções múltiplas - heurística, demonstrativa, didática, reflexiva, filosófica -, cujo peso relativo varia segundo os locais e os públicos aos quais se dirige (PESTRE, 1996, p. 37).

Tais considerações, então, incluem, nos parece, o saber escolar como uma forma de saber científico, como um modo das práticas científicas se expressarem. Desse modo, diferentemente de considerar dois regimes diferentes de saber - como fazem a história e a didática das disciplinas escolares -, busca-se um mapeamento histórico de análise de como as práticas científicas foram ganhando expressão e universalizando-se, isto é, sendo apropriadas e reeelaboradas em diferentes contextos.

\section{Saberes científicos e escolares: para além das interpretações disci- plinar e didática}

Belhoste $(1995)^{3}$, numa conferência realizada no INRP - Institut National de Recherche Pédagogique, Paris, em janeiro de 1995, destacou o caráter restrito dos modelos disciplinar e didático para compreensão dos saberes escolares. Sobre o primeiro, Belhoste (1995) frisou que Chervel (1990) apoiouse principalmente no caso do ensino francês para construir sua autonomia das disciplinas. Assim, pergunta Belhoste:

...mas o historiador deve utilizar tal noção (de disciplina) de maneira tão pouco inocente, tão pensada, tão trabalhada, tão penetrada pela cultura professoral, sempre. A evolução dos ensinos literários pode sem dúvida legitimamente ser interpretada como um processo de disciplinarização, dado que a noção de disciplina escolar é no fundo uma teorização pelos modelos desses ensinos. Mas o que dizer dos ensinos científicos no liceu, considerados durante muito tempo como especialidades onde a promoção ao "status" de disciplinas se explica por atração ao modelo das humanidades que eles tratam de imitar? (1995, p. 2).

A partir dessa interrogação, Belhoste busca evidenciar que a noção de disciplina escolar possui uma história própria - um conceito útil para estu- 
dar a história dos ensinos das humanidades em nível secundário na França no período compreendido entre 1850 e 1950. Desse modo, torna-se anacrônico o uso do conceito de disciplina escolar, para compreender o significado de todo e qualquer saber escolar, como categoria histórica.

As observações de Belhoste (1995), com respeito ao trabalho de Chervel (1990), alertam-nos para o reducionismo que cometeríamos se tentássemos enquadrar a trajetória de qualquer saber escolar, em qualquer época, nos limites do modelo disciplinar. Não caberia, portanto, ao pesquisador dos saberes escolares, confinar-se na história da ambiência escolar para dela retirar os conteúdos de ensino nela produzidos sob a forma de exposição, exercícios, técnicas e provas.

Relativamente à didática das disciplinas, Belhoste destaca as razões para o sucesso do modelo de Chevallard:

....ele intenta dar conta do que ocorreu com a reforma da matemática moderna, construindo um esquema grosseiro do que se passou na França no curso dos anos 60-70, possibilitando um quadro teórico cômodo à didática das disciplinas alojadas nos IREM (centros de pesquisa em educação matemática); ao mesmo tempo, fornece aos didáticos das disciplinas uma justificativa para sua intervenção contra os especialistas universitários de cada disciplina (1995, p. 4).

Mas, o modelo da transposição didática não serve como categoria histórica para fins de compreensão do significado dos saberes escolares. Tal teoria descontextualiza radicalmente "a situação didática", reduzindo o mundo exterior (fora da escola) a um conjunto de referências que o colocam entre parênteses. O modelo é um modelo fechado. (BELHOSTE, 1995, p. 4). O autor ressalta, ainda, que a busca da compreensão de como se organizaram os saberes deve seguir, justamente, a marcha contrária àquela proposta pela transposição, isto é, a saída de um modelo fechado para a construção de esquemas abertos que levem em conta a extensão, a diversidade e a temporalidade própria do mundo social.

A crítica central ao modelo da transposição didática fundamenta-se nas redefinições que vêm sendo elaboradas pela NHC. Sem mencionar diretamente a NHC, Belhoste (1995) coloca em xeque a lógica global do modelo destacado que um de seus elementos principais, o savoir savant (saber científico) representa uma vaga noção já abandonada pela história das ciências. Ao que poderíamos acrescentar, que o modelo chevallardiano utiliza o conceito reificado de ciência.

A partir das redefinições produzidas pela NHC é possível rejeitar modelos que intentam engessar o desenrolar histórico. Assim, a grande contri- 
buição da NHC, para o entendimento do significado dos saberes escolares, situa-se no alerta de que todo saber escolar para ser estudado deve levar em conta a reconstrução dos contextos específicos de sua produção e apropriação. Assim, por exemplo, a constituição do ensino da geometria descritiva foge completamente aos modelos disciplinar e didático. Não foi criada no interior de uma comunidade de cientistas e repassada para o meio escolar. A geometria descritiva foi criada no interior das escolas de engenharia da França no fim do século XVIII (BELHOSTE, 1995). Por outro lado, toda matemática escolar ensinada no Brasil, sobretudo até as primeiras décadas do século XX, - época em que as sociedades científicas e a produção matemática são organizadas - representa uma apropriação originária dos manuais escolares franceses (VALENTE, 1999).

Os novos significados atribuídos às práticas científicas pela NHC permitem afastar modelos prontos que poderiam conformar e explicar as relações entre os saberes científicos e escolares de modo anistórico, isto é, modelos aplicáveis em qualquer época e lugar da trajetória de constituição dos saberes. Assim, o modelo disciplinar pode bem servir num tempo dado (1850-1950) e, para certos saberes (as humanidades clássicas), se mostrará inconveniente para a escolarização dos saberes científicos. Tampouco goza do privilégio universalista o modelo da transposição didática, que congela os saberes de referência (ciências) para explicar a constituição dos saberes escolares.

\section{Nova História das Ciências: elementos para reflexão sobre a Didática}

No âmbito da história das disciplinas, Chervel (1990) elabora sua concepção de relacionamento entre os saberes científico e escolar, retomando concepções tradicionais, para buscar ultrapassá-las. O autor destaca que é comum pensar que a escola ensina o que ensina a mando das comunidades científicas. Comum também, segundo o autor, é a idéia de vulgarização científica, isto é, a tarefa da escola de ensinar vulgarizações científicas. Acionando a Pedagogia e a Didática, o meio escolar seria encarregado de, didatizando o saber científico, transformá-lo em uma vulgarização. À Didática, então, caberia a tarefa de construir essas vulgarizações de modo a tornar palatável o saber científico. Tudo muda, segundo o autor, quando se pensa na originalidade dos conteúdos escolares, relativamente à sua origem, desenvolvimento, história. A essas ponderações, acrescentaríamos que, sob a perspectiva da história das disciplinas, tudo muda também, relativamente à Didática. De agente externo aos saberes científicos, buscando vulgarizá-los, a Didática constituiria elemento intrínseco aos saberes escolares, ingrediente de sua própria produção ao longo do tempo. $\mathrm{O}$ calcanhar de Aquiles dessa concepção, no entanto, é o de tentar impor o modelo disciplinar a todos os saberes e em qualquer tempo histónico. 
O trabalho de Chevallard (1991), como o próprio autor deixa claro desde o início de sua obra, tem objetivos diretamente relacionados à Didática. Depois de analisar a tríade professor-aluno-saber, o autor declara que a Didática e, em particular, a Didática da Matemática, encontra-se numa fase préhistórica do ponto de vista de sua cientificidades. Segundo Chevallard (1991), para dar um status científico a essa didática, toma-se necessário centrar a atenção não na tríade, mas em um dos seus elementos: o saber escolar. Assim fazendo e, elaborando um sofisticado modelo dinâmico de relação entre os saberes, o autor, nos parece, cria a figura de um novo personagem: o didático. Trata-se de alguém que não é professor e nem cientista. $O$ didático é o profissional que estuda as ações praticadas na noosfera. Essas ações, realizadas com as crises do saber ensinado, transferem fluxos do saber científico para o saber escolar. É desse modo que Chevallard (1991) buscou dar autonomia à esfera didática e erigi-la a campo científico. Porém, ao fazer isso, construiu um modelo que não dá conta, em grande medida, da complexidade que envolve os saberes e sua produção e apropriação.

A redefinição do entendimento do que são práticas científicas, operadas pela NHC, dá-nos a possibilidade de perceber os saberes escolares como uma das formas de apropriação e reelaboração das práticas científicas. Isso supera o modo de perceber as relações entre saberes, posto pelas perspectivas da história das disciplinas e da didática das disciplinas. Tais bases teóricas alicerçam-se sobre a premissa da separação entre ensino e produção científica, além de tomar a ciência como, essencialmente, um conjunto abstrato de teorias, elaboradas em espaços restritos por cientistas stricto sensu. Desse modo, subjaz a ambas as perspectivas mencionadas - por enquanto hegemônicas na orientação de trabalhos na área da Didática - a idéia de que a produção científica, separada dos contextos sociais, políticos, econômicos, culturais, pronta e acabada por cientistas profissionais, estaria sempre no aguardo de sua transmissão, como corpo teórico intacto, para outras searas que dela tivessem necessidade.

Em síntese, caberia reiterar que os estudos, no âmbito da Didática, deveriam levar em conta que a produção científica está sempre envolvida em contextos específicos, responsáveis por seu desenvolvimento, e é parte integrante dessa produção, a sua reprodução. Assim, o ensino caracteriza-se como uma de suas modalidades. A análise dessa modalidade de reprodução revela não somente 0 caráter importante da transmissão do saber, mas também 0 papel que o ensino tem na própria constituição dos saberes científicos. 


\section{Notas}

1 Em nossa Dissertação de Mestrado elaboramos um capítulo denominado "Saber Científico e Saber Escolar" onde realizamos um inventário bibliográfico e fizemos uma análise dos textos que tratavam do tema do "saber escolar" (Valente 1991).

2 A título de um exemplo, veja-se Develay (1995) que reúne textos que utilizam a transposição didática em diversas disciplinas como artes plásticas, educação física, francês, geografia, história, inglês, música, filosofia, física, ciências econômicas e sociais, biologia.

3 Bruno Belhoste é pesquisador da história dos saberes científicos junto ao INRP- InstitutNational de Recherche Pédagogique de Paris e autor de vários livros, dentre eles, dirigiu a obra La formation polytechnienne, Paris: Dunod; escreveu Lês sciences dansl'enseignement secondaire français, Paris: Econômica e organizou o livro Lês sciences au lycée, Paris: INRP/Vuibert.

\section{Referências}

BELHOSTE, B. Resume de l'exposé de Bruno Belhoste. Paris: INRP, 1995.

. Pour une reevaluation du role de l'enseignement dans l'histoire des mathématiques. Revued'histoire desmathématiques, Paris, n. 4, p. 289-304, 1998.

Bkouche, R. Variations autour de la réforme de 1902/1905. In: GISPERT, Hélène et al : La France Mathématique. Paris: Cahiers d'Histoire et de Philosophie des Sciences et Société Mathématique de France, 1991.

CHERVEL, A. História das disciplinas escolares: reflexões so bre um campo de pesquisa. Teoria \& Educação, Porto Alegre, n. 2, 1990.

CHEVALLARD, Y. La transposition didactique: du savoir savant au savoir au savoir enseigné. Grénobre: La Pensée Sauvage, 1991.

DEVELAY, M. Por uma nova história social e cultural das ciências: novas definições, novos objetos, novas abordagens. Cadernos IG/UNICAMP, Campinas, v 6, n. 1, 1995. déc. 1998.

Lês sciences et l'histoire aujoud'hui. Lê débat, Paris, n. 102, nov. /

VALENTE, W. R. Cotidiano Escolar: prática pedagógica e saber docente. São Paulo, SP, 1991. Dissertação ( Mestrado) - PUCSP, 1991.

Uma história da matemática escolar no Brasil, 1730-1930. São Paulo, SP: Annablume: FAPESP, 1991.

Recebido em 15/03/2003

Aprovado em 17/06/2003 